Check for updates

Cite this: RSC Adv., 2018, 8, 2157

Received 16th November 2017 Accepted 30th December 2017

DOI: $10.1039 / c 7 r a 12499 f$

rsc.li/rsc-advances

\section{Dimeric cinchona ammonium salts with benzophenone linkers: enantioselective phase transfer catalysts for the synthesis of $\alpha$-amino acids $\uparrow$}

\author{
Seunga Woo, Yong-Gyun Kim, Baegeun Lim, Jiin Oh, Yeonji Lee, Hyeri Gwon \\ and Keepyung Nahm (D) *
}

Chiral phase transfer catalysts of dimeric cinchona ammonium salts linked with a benzophenone bridge showed high enantioselectivity in the $\alpha$-alkylation of a glycinate ester under mild industry-applicable conditions: $0.5 \mathrm{~mol} \%$ PTC and near equivalents of alkyl halide. A dual function of the dimeric quinuclidiniums was proposed for the high efficiency.
Since cinchona alkaloids were transformed to asymmetric quaternary quinuclidinium salts with benzyl halides and were used as a phase-transfer catalyst (PTC) (1) by Dolling ${ }^{1}$ and O'Donnell, ${ }^{2}$ cinchona alkaloids have been widely utilized as chiral templates for phase-transfer catalysis. ${ }^{3}$ (Scheme 1) These organic PTCs can be easily prepared from natural and low cost chiral cinchona alkaloids in a few synthetic steps and they are stable and facile under normal reaction conditions in water. Later $N$-9-anthracenylmethyl quinuclidinium salt PTC (2) was introduced and showed high enantioselectivity for the alkylation of the protected glycine tert-butyl ester. ${ }^{4}$ Quinuclidinium PTCs with each pseudo-enantiomeric cinchona alkaloids, such as $(-)$-cinchonidine and $(+)$-cinchonine, show enantiomeric selectivity each other, and have been successfully applied in various asymmetric organic synthesis including $\alpha$-alkyl glycine

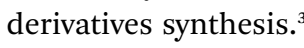

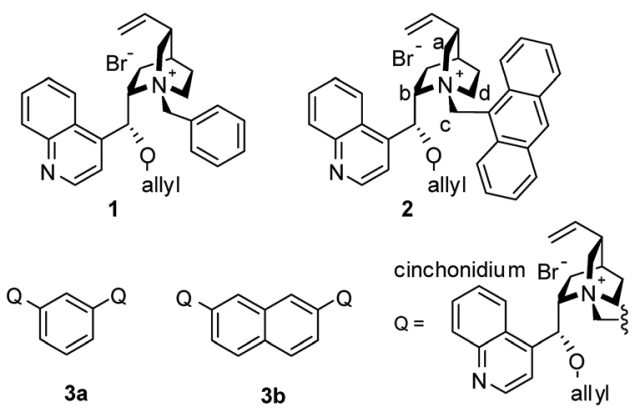

Scheme 1 Representative cinchona-derived PTCs.

School of Chemistry and Biochemistry, Yeungnam University, 280 Daehak-Ro, Gyeongsan, Gyeongbuk 38541, Republic of Korea. E-mail: kpnahm@yu.ac.kr

$\dagger$ Electronic supplementary information (ESI) available. See DOI: $10.1039 / \mathrm{c} 7 \mathrm{ra} 12499 \mathrm{f}$
Enantioselectivity in the alkylation of glycine esters has been probed by several experimental trials. Crystallographic study of the $p$-nitrophenoxide salt of PTC 2 showed that $N$-anthracenylmethy moiety of $\mathbf{2}$ is located in staggered position between the $\mathrm{C}^{\mathrm{c}}$ and the $\mathrm{C}^{\mathrm{d}}{ }^{4 a}$ which provides more hindered spaces around the $\mathrm{C}^{\mathrm{b}}-\mathrm{C}^{\mathrm{c}}-\mathrm{C}^{\mathrm{d}}$ face (F4) around the ammonium. ${ }^{5} \mathrm{The}^{\mathrm{a}}-$ $\mathrm{C}^{\mathrm{b}}-\mathrm{C}^{\mathrm{d}}$ face (F2) is blocked by O-allyl group and the $\mathrm{C}^{\mathrm{a}}-\mathrm{C}^{\mathrm{c}}-\mathrm{C}^{\mathrm{d}}$ face (F3) are covered by bicyclic ring, but the $\mathrm{C}^{\mathrm{a}}-\mathrm{C}^{\mathrm{b}}-\mathrm{C}^{\mathrm{c}}$ face (F1) is less hindered. Therefore, anionic glycinate derivatives could approach toward the F1. Enolates of glycine esters would form tight ionic complexes with the ammonium nitrogen on the F1 face of PTC 2, and the alkylation with alkyl halides could follow along the direction of less hindered side of the si/re-face of the enolates. ${ }^{4 a}$

NOE correlations study of PTC 2 with borohydride ion ${ }^{6}$ indicated the borohydride occupies the F1 face of PTC 2 . Computational simulation ${ }^{7}$ also described the stable transition states where an enolate locates on the F1 face.

Dimeric cinchona-derived PTCs linked by either benzene or naphthalene ligand have been introduced by Park et al. ${ }^{\text {sa-c }}$ Among ortho, meta and para-connected PTCs, the meta-disubstituted phenyl PTC 3a or 2,7-disubstituted naphthyl PTC $\mathbf{3 b}$ showed highly improved catalytic effects compared to monomeric PTC 2, such as lower dosage of catalyst (1-5 mol\%) and high enantioselectivity. Role of additional quinuclidinium was thought to be a steric blocker which could increase the stereoselectivity of the enolate complex on the F1 face.

Other dimeric cinchona alkaloid PTCs were also developed with various linkers, such as 9,10-dimethylanthracenyl, ${ }^{9}$ biphenyl, alkenyl, ${ }^{10}$ macrocyclic amine and calixarene,${ }^{11}$ and their enantioselectivities were equal or lower than those of monomeric PTCs. Some dimeric PTCs were converted to ionic polymers by replacing bromides to a disufonate anion without loss of reactivity and enantioselectivity. ${ }^{12}$ 
<smiles>O=C(c1ccccc1)c1ccc(O)cc1</smiles>

$4 p$<smiles>O=C(c1ccc(O)cc1)c1ccc(Cl)cc1</smiles><smiles>O=C(c1ccc(O)cc1)c1ccc(O)cc1</smiles><smiles>O=C(c1cccc(O)c1)c1cccc(Cl)c1</smiles>

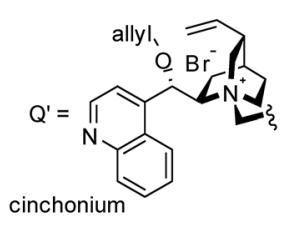

Scheme 2 Monomeric and dimeric cinchona-PTC with a benzophenone bridge.

Alkylation of tert-butyl glycinate ester was performed with 1$10 \mathrm{~mol} \%$ of PTC 1-3 and excess 5 equivalents of alkyl halide at 0 to $-78{ }^{\circ} \mathrm{C}$. These catalytic conditions are still to be improved for practical application; low mol\% of PTC, near equimolar amount of alkyl halides and ambient temperature. Hence we investigated dimeric PTCs with various linkers for facile catalytic condition. Here we introduce new dimeric cinchona PTCs with a benzophenone linker and their application in asymmetric alkylation of glycine derivatives.

Monomeric PTC 4p, $N$-(4-benzoylbenzyl)-O(9)allylcinchonidium bromide, which has a benzoyl benzyl at N(1), was synthesized from 4-bromomethyl-benzophenone and (-)-cinchonidine. (Scheme 2) Dimeric cinchona-based quarternay ammonium salts (PTC 5-6) were synthesized from meta/paradi(bromomethyl) benzophenone ${ }^{13}$ and two equivalent cinchona alkaloids. Coupling reaction of the di(bromomethyl)benzophenone and (-)-cinchonidine or (+)-cinchonine in EtOH/DMF/ $\mathrm{CHCl}_{3}(5: 6: 2)^{8}$ for $5 \mathrm{~h}$ at $100{ }^{\circ} \mathrm{C}$ and the $\mathrm{O}(9)$-allylation with allyl bromide gave the dimeric quarternary salts, bis(4-(O)(9)-allyl-cinchonidium- $N$-methyl)phenyl) methanone dibromide (5) and bis(4-(O(9)-allyl-cinchonium- $N$-methyl)phenyl) methanone dibromide (6), respectively, in good yields.

Enantioselective PTC 4-6 system was applied in the alkylation of $N$-(diphenylmethylene)glycine tert-butyl ester (7) to the $\alpha$-alkylated glycinate (8) under the condition of $0.5-1.0 \mathrm{~mol} \%$ catalysts and 1.2 equivalent alkyl halides. We also explored the variation of enantioselectivity depending on the various positions of dimeric cinchonidium at benzophenone; $5 \mathbf{p p}, 5 \mathrm{mp}$ and $5 \mathbf{m m}$.

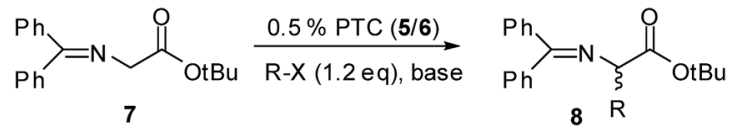

Monomeric PTC 4p showed enantioselectivity of $87 \%$ ee (S) at $25{ }^{\circ} \mathrm{C}$ (Table 1 , entry 1 ) which is slightly higher than $81 \%$ ee of $N$-benzyl PTC $1 .^{2}$ Geometric difference between PTC $\mathbf{1}$ and $\mathbf{4 p}$ is the extra $p$-benzoyl substituent on $N$-benzyl. Apparently the $p$ benzoyl moiety gives no big enhancement in enantioselectivity of 4 p.

$\$$ For the detailed synthesis of 5pp, 6pp and their precursors, see ESI. $\dagger$
When the dimeric PTC of bis(4- $(\mathrm{O}(9)$-allyl-cinchonidium- $N$ methyl)phenyl)methanone dibromide (5pp) was applied in the benzylation, it showed big improvement of both enatioselectivity and catalytic condition.§ PTC 5pp (1.0 mol\%) showed enantioselectivity of $97 \%$ ee (S) with 1.2 equivalents of benzyl bromide at $20^{\circ} \mathrm{C}$. (entry 2) At lower reaction temperature $\left(0{ }^{\circ} \mathrm{C}\right.$ : entry 3), its enantioselectivity increased to $98 \%$ ee. When $0.5 \mathrm{~mol} \%$ of $5 \mathrm{pp}$ was applied at 0 and $-20{ }^{\circ} \mathrm{C}$, the product showed 98\% and 99\% ee. (entries 4 and 6) And with $0.25 \mathrm{~mol} \%$ of 5pp, the enantioselectivity went down to $97 \%$ ee. Therefore, the practical catalytic condition for the benzylation with $\mathbf{5 p p}$ would be $0.5 \mathrm{~mol} \%$ of PTC and 1.2 equivalents of benzyl bromide at $0{ }^{\circ} \mathrm{C}$.

The isomeric PTC $\mathbf{5 m p}$ and $\mathbf{5 m m}$ showed lower \% ee; $\mathbf{5 m p}$ showed $89 \%$ ee (S) in benzylation (entry 8 ) and $\mathbf{5 m m}$ showed $71 \%$ ee (entry 9). These enatioselectivity values are similar or lower than that of the monomeric 4p. There was no enhanced catalytic effect by two cinchonidiums at meta/para and metal meta position of $5 \mathrm{mp}$ and $5 \mathrm{~mm}$.

Enantioselectivity of PTC 5 was varied in the order of 5pp > $\mathbf{5 m p}>\mathbf{5 m m}$ depending on the position at benzophenone ring, which is different from those observed at PTC 3a (meta $>$ para $>$ ortho position). ${ }^{8}$ To deduce the enantioselectivity of PTC 5pp, one may consider a distance factor between dimeric cinchonidiums. The distance between two benzyl positions of the bridge benzophenone of PTC 5pp was calculated to be $\sim 10.4 \AA$ at B3LYP/6-31G(d) level (see, ESI $\dagger$ ), which is longer than those of PTC 3a and $3 \mathbf{b}(\sim 5.1 \AA$ and $\sim 7.5 \AA$, respectively $)$. And those of PTC 5pm and $5 \mathrm{~mm}$ were $8.7 \AA$ and $8.3 \AA$, respectively. The distance between two quarternary ammoniums could not be correlated with the enantioselectivity, and it would not be a main controlling factor for enantioselectivity.

At the transition state for $\alpha$-alkylation of glyciante 7 with benzyl bromide, there will be $\mathrm{S}_{\mathrm{N}} 2$-type bond formation/cleavage between the enolate carbon and the benzyl carbon and bromide, which occurs on the F1 face of the PTC. ${ }^{7 \boldsymbol{b}}$ (Fig. 1) It is expected that the anionic oxygen of the enolate from 7 will form an ionic complex with the PTC ammonium at the transition state, and as the benzyl bromide approaches to the enolate of 7 in $\mathrm{S}_{\mathrm{N}} 2$ pattern, the leaving bromide will be attracted also by the

$\S$ General alkylation procedure: Benzyl bromide $(14.5 \mu \mathrm{L}, 0.122 \mathrm{mmol})$ was added to a solution of $\mathrm{N}$-(diphenylmethylene) glycine tert-butyl ester $(7,30 \mathrm{mg}, 0.102$ mmol) and the catalyst $5 \mathrm{pp}\left(50 \mu \mathrm{L}, 1 \times 10^{-2} \mathrm{M}\right.$ in $\mathrm{CH}_{2} \mathrm{Cl}_{2}, 0.5 \mathrm{~mol} \%$, the diluting solvent was evoporated) in toluene/chloroform $(7: 3,0.75 \mathrm{~mL})$. The solution was then cooled $\left(0{ }^{\circ} \mathrm{C}\right)$, purged with nitrogen $(10 \mathrm{~min})$, and aqueous $50 \% \mathrm{KOH}\left(0.25 \mathrm{~mL}, 22\right.$ equiv.) was added. The suspension was stirred at $0{ }^{\circ} \mathrm{C}$ until the starting material had been consumed $(3 \mathrm{~h})$. The reaction mixture was diluted with diethyl ether $(20 \mathrm{~mL})$, washed with saturated $\mathrm{NaBr}$ aqueous solution $(3 \times 5 \mathrm{~mL})$. Organic layer was dried over $\mathrm{MgSO}_{4}$, filtered, and concentrated. Purification by flash column chromatography on silica gel (hexanes/EtOAc $98: 2$ ) afforded the desired product 8 (37 $\mathrm{mg}, 95 \%$ yield) as a colourless oil. Enantioselectivity was determined by chiral HPLC analysis

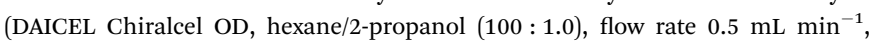
$25{ }^{\circ} \mathrm{C}, \lambda=254 \mathrm{~nm}$, retention times: $\mathrm{R}$ (minor) $12.5 \mathrm{~min}, \mathrm{~S}$ (major) $20.5 \mathrm{~min}$, $98 \%$ ee). The absolute configuration was confirmed by comparison of the HPLC retention time with the authentic sample synthesized by the reported procedure..$^{2,4,8}$ 
Table 1 Catalytic phase-transfer benzylation of 7 with monomeric and dimeric cinchona-based catalysts (4-6) ${ }^{a}$

.

\begin{tabular}{|c|c|c|c|c|c|c|}
\hline \multirow[b]{2}{*}{ Entry } & \multirow[b]{2}{*}{ PTC } & \multirow[b]{2}{*}{$\mathrm{mol} \%$} & $\begin{array}{l}\mathrm{PTC} 4-6 \\
\mathrm{PhCH}_{2} \mathrm{Br}(1.2 \mathrm{eq}) \\
\mathrm{PhCH}_{3} / \mathrm{CHCl}_{3}(7: 3) \\
50 \% \text { aq KOH }\end{array}$ & $\left.{ }_{\mathrm{Ph}}^{\mathrm{Ph}}\right\rangle=\left.\mathrm{N}\right|_{\mathrm{Bn}} ^{*}$ & \multirow[b]{2}{*}{ Yield $^{b}(\%)$} & \multirow[b]{2}{*}{$\% \mathrm{ee}^{c}$ (config) } \\
\hline & & & Temp $\left({ }^{\circ} \mathrm{C}\right)$ & Time (h) & & \\
\hline $1^{e}$ & $4 p$ & 5.0 & 20 & 1.5 & 89 & $87(S)$ \\
\hline 2 & $5 p p$ & 1.0 & 20 & 2 & 92 & $97(S)$ \\
\hline 3 & $5 p p$ & 1.0 & 0 & 3 & 95 & $98(S)$ \\
\hline 4 & $5 p p$ & 0.5 & 0 & 4 & 95 & $98(\mathrm{~S})$ \\
\hline 5 & $5 p p$ & 0.25 & 0 & 8 & 94 & $97(S)$ \\
\hline 6 & $5 p p$ & 0.5 & -20 & 6 & 95 & 99 (S) \\
\hline $7^{f}$ & $5 p p$ & 0.5 & 0 & 6 & 95 & $98(\mathrm{~S})$ \\
\hline 8 & $5 \mathrm{mp}$ & 2.0 & 20 & 1.5 & 89 & $89(\mathrm{~S})$ \\
\hline 9 & $5 \mathrm{~mm}$ & 2.0 & 20 & 1.5 & 84 & $71(S)$ \\
\hline 10 & $6 p p$ & 0.5 & 20 & 3 & 90 & $94(\mathrm{R})$ \\
\hline 11 & $6 p p$ & 0.5 & 0 & 6 & 92 & $95(\mathrm{R})$ \\
\hline 12 & $6 p p$ & 0.5 & -20 & 8 & 93 & $98(\mathrm{R})$ \\
\hline
\end{tabular}

${ }^{a}$ Benzylation of $7(0.1 \mathrm{mmol})$ was carried out with 1.2 equivalents of benzyl bromide and $50 \%$ aqueous $\mathrm{KOH}(0.25 \mathrm{~mL})$ in toluene/chloroform $(7: 3$, $0.75 \mathrm{~mL}$ ) under nitrogen atmosphere, unless otherwise stated. ${ }^{b}$ Yields of isolated product. ${ }^{c}$ Enantiopurity of 8 was determined by HPLC analysis using a column with a chiral stationary phase (DAICEL Chiralcel OD) with hexane/isopropanol as the solvent. ${ }^{d}$ The absolute configuration was determined by comparison of the HPLC retention time with that of an authentic sample, which was synthesized independently by reported procedures..$^{2,4,8} e$.0 equivalents of benzyl bromide. ${ }^{f}$ With the same conditions expect the increased amount of 7 (1.0 mmol).

ammonium. ${ }^{\mathbf{1 4}}$ An estimated distance between enolate and the leaving bromide will be $\sim 5.0 \AA$.

At the monomeric PTC $\mathbf{1} / \mathbf{2}$, both the enolate and bromide will be attracted by the same quinuclidinium. On the other hand, dimeric PTC 5 is expected to anchor the enolate of gylcinate 7 on one ammonium and attract the leaving bromide with another ammonium in a distance $(\mathrm{Br}-\mathrm{N}(+))$ of $\sim 5.0 \AA$ at TS. (Fig. 1) Two phenyl rings of the benzophenone bridge of PTC 5 are not laid on a plane but twisted around the carbonyl $(\tau=$ $\left.50^{\circ}\right)^{15}$ and these two twisted cinchonidiums of PTC 5pp would provide a stabilized transition structure for the benzylation within $\sim 10 \AA$ distance by dual functions of two quinuclidiniums. However, more crowded TSs will be formed in $\mathbf{5 m p}$ and $\mathbf{5 m m}$ because of the short ammonium distance, therefore their TSs will resemble to that of monomeric PTC 4p.

Dimeric PTC of bis(4-(O(9)-allyl-cinchonium- $N$-methyl) phenyl) methanone dibromide (6pp) derived from (+)-cinchonine is a pseudo enantiomer of PTC 5pp. PTC 6pp showed also high enantioselectivity of $94 \%$ ee (R) in the benzylation at room

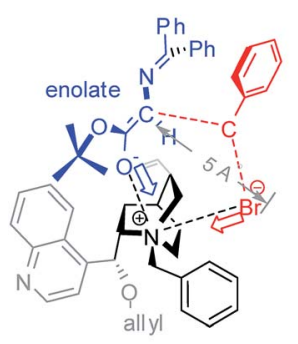

TS (1 /enolate/Bn-Br)

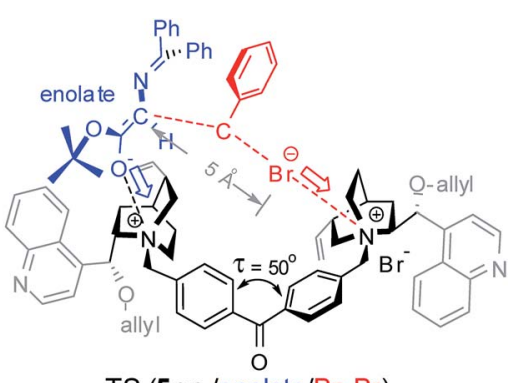

TS (5pp /enolate/Bn-Br)
Fig. 1 Proposed TSs for benzylation of an enolate of gylcinate with PTC 1 and 5pp. temperature. (entry 10) Its selectivity increased to $95-98 \%$ ee at lower temperature (entries 11 and 12).

The alkylation with selected alkyl halides with $0.5 \mathrm{~mol} \%$ of PTC 5pp were summarized in Table 2. The results showed that 5pp has high enantioselectivity of 93-97\% ee with allyl bromide derivatives and 93-98\% ee with benzyl bromide derivatives. Alkyl iodides were also alkylated in high \% ee (Table 2, entries 7 and 8), but tert-butyl bromoacetate showed low 85\% ee at the same condition because of the known background reaction. ${ }^{\mathbf{1 6}}$ (entry 9) PTC 5pp has been proved to be an advanced phase transfer catalyst for the synthesis of various $\alpha$-amino acids under mild catalytic conditions.

$\alpha, \alpha$-Dialkylation of aldimine Schiff base of amino acid $^{17}$ was examined with 5pp. Aldimine Schiff base of D,L-alanine ethyl ester 9, benzyl bromide (1.2 eq.) and $\mathrm{CsOH} \cdot \mathrm{H}_{2} \mathrm{O}(5$ eq.) with PTC 5 pp $(1.0 \mathrm{~mol} \%)$ in toluene $/ \mathrm{CHCl}_{3}(7: 3)$ at $-10{ }^{\circ} \mathrm{C}$ for 4 hour, then the acid work-up gave ethyl 2-amino-2-methyl-3phenylpropionate 10 in $94 \%$ yield, which was benzoylated to $N$-benzoyl $\alpha, \alpha$-dialkylated product $\mathbf{1 1}$ and analysed with chiral HPLC (92\% ee (S)).

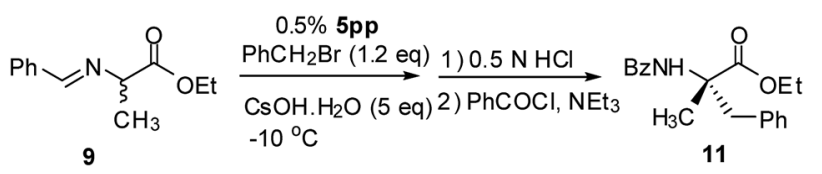

In conclusion, we have provided the novel dimeric cinchonabased PTCs with a benzophenone bridge. The $p, p^{\prime}$-linked PTC 5pp and 6pp showed high enantioselectivity (93-99\% ee) in the alkylation of a glycine ester under mild catalytic conditions of $0.5 \mathrm{~mol} \%$ PTC and near stoichiometric alkyl halide (1.2 equivalents) at $0-20{ }^{\circ} \mathrm{C}$. Dialkylation under similar conditions gave high \% ee with the aldimine Schiff base of alanine. Their 
Table 2 Catalytic phase-transfer alkylation of 7 with dimeric cinchona-based catalyst $5 \mathrm{pp}^{a}$

\begin{tabular}{|c|c|c|c|c|}
\hline \multirow[b]{3}{*}{ Entry } & \multirow[b]{3}{*}{$\mathrm{R}-\mathrm{X}$} & \multirow{2}{*}{$\begin{array}{l}5 \mathrm{pp}(0.5 \mathrm{~mol} \%) \\
\mathrm{R}-\mathrm{X}(1.2 \mathrm{eq}) \\
\mathrm{PhCH}_{3} / \mathrm{CHCl}_{3}(7: 3) \\
50 \% \text { aq } \mathrm{KOH}, 0^{\circ} \mathrm{C}\end{array}$} & & \multirow[b]{2}{*}{ OtBu } \\
\hline & & & & \\
\hline & & Time (h) & Yield $^{b}(\%)$ & $\%$ ee $(\text { config) })^{c}$ \\
\hline 1 & $\mathrm{PhCH}_{2}-\mathrm{Br}$ & 4 & 95 & $98(S)$ \\
\hline 2 & & 11 & 89 & $97(S)$ \\
\hline 3 & & 12 & 86 & $97(S)$ \\
\hline 4 & & 3 & 88 & $93(S)$ \\
\hline 5 & & 9 & 69 & $95(\mathrm{~S})$ \\
\hline 6 & & 9 & 93 & $94(\mathrm{~S})$ \\
\hline $7^{d}$ & $\mathrm{CH}_{3} \mathrm{CH}_{2} \mathrm{I}$ & 6 & 92 & $95(\mathrm{~S})$ \\
\hline $8^{d, e}$ & $\mathrm{CH}_{3} \mathrm{I}$ & 4 & 64 & $93(\mathrm{~S})$ \\
\hline 9 & & 5 & 51 & $85^{f}(\mathrm{~S})$ \\
\hline
\end{tabular}

${ }^{a}$ Alkylation of $7(0.1 \mathrm{mmol})$ was carried out with $0.5 \mathrm{~mol} \%$ of $5 \mathrm{pp}, 1.2$ equivalents of R-X and $50 \%$ aqueous $\mathrm{KOH}(0.25 \mathrm{~mL})$ in toluene/ chloroform $(7: 3,0.75 \mathrm{~mL})$ at $0{ }^{\circ} \mathrm{C}$ under nitrogen atmosphere, unless otherwise noted. ${ }^{b}$ Yields of isolated product. ${ }^{c}$ Enantiopurity of 8 was determined by HPLC analysis using a column with a chiral stationary phase (DAICEL Chiralcel OD) with hexane/isopropanol as the solvent. The absolute configuration was determined by comparison of the HPLC retention time with that of an authentic sample, which was synthesized independently by reported procedures. ${ }^{2,4,8}{ }^{d}$ R-I (5.0 eq.) and $\mathrm{CsOH} \cdot \mathrm{H}_{2} \mathrm{O}$ (5.0 eq.) was uses as base. ${ }^{e}$ With $1.0 \mathrm{~mol} \%$ of the catalyst. ${ }^{f} \mathrm{~N}$-Benzoyl derivative.

efficiency and enantioselectivity were explained by dual functions dimeric cinchonidiums; one as an alkylating site and another as a receptor for a leaving anion. Novel PTCs 5pp and 6pp would be applied in the synthesis of natural and nonnatural chiral $\alpha$-amino acids and their derivatives. Applications to other asymmetric phase-transfer catalytic reactions with $\mathbf{5 p p}$ are under investigation.

\section{Conflicts of interest}

There are no conflicts to declare.

\section{Acknowledgements}

This study was supported by the National Research Foundation of Korea (NRF) grant funded by the Korean Government (2013R1A1A2066041).

\section{Notes and references}

1 U.-H. Dolling, P. Davis and E. J. J. Grabowski, J. Am. Chem. Soc., 1984, 106, 446.

2 M. J. O'Donnell, W. D. Benett and S. Wu, J. Am. Chem. Soc., 1989, 111, 2353.
3 For reviews, see: (a) M. J. O'Donnell, Acc. Chem. Res., 2004, 37, 506; (b) B. Lygo and B. I. Andrews, Acc. Chem. Res., 2004, 37, 518; (c) S.-s. Jew and H.-g. Park, Chem. Commun., 2009, 7090; (d) S. Shirakawa and K. Maruoka, Angew. Chem., Int. Ed., 2013, 52, 4312; (e) K. Brak and E. N. Jacobsen, Angew. Chem., Int. Ed., 2013, 52, 534.

4 (a) E. J. Corey, F. Xu and M. C. Noe, J. Am. Chem. Soc., 1997, 119, 12414; (b) B. Lygo and P. G. Wainwright, Tetrahedron Lett., 1997, 38, 8595.

5 When the priority of substituents around ammonium is in the order of $\mathrm{C}^{\mathrm{a}}>\mathrm{C}^{\mathrm{b}}>\mathrm{C}^{\mathrm{c}}>\mathrm{C}^{\mathrm{d}}$, one can assume a tetrahedral structure with four carbons and four faces of the tetra-alkyl ammonium; $\mathrm{F} 1\left(\mathrm{C}^{\mathrm{a}}-\mathrm{C}^{\mathrm{b}}-\mathrm{C}^{\mathrm{c}}\right), \mathrm{F} 2\left(\mathrm{C}^{\mathrm{a}}-\mathrm{C}^{\mathrm{b}}-\mathrm{C}^{\mathrm{d}}\right)$, F3 $\left(C^{\mathrm{a}}-\mathrm{C}^{\mathrm{c}}-\mathrm{C}^{\mathrm{d}}\right)$ and F4 $\left(\mathrm{C}^{\mathrm{b}}-\mathrm{C}^{\mathrm{c}}-\mathrm{C}^{\mathrm{d}}\right)$.

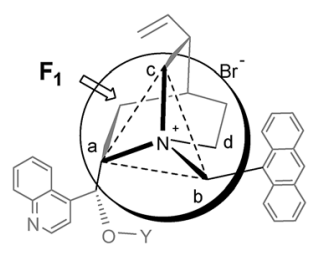

6 C. Hofstetter, P. S. Wilkinson and T. C. Pochapsky, J. Org. Chem., 1999, 64, 8794.

7 (a) C. E. Cannizzaro and K. N. Houk, J. Am. Chem. Soc., 2002, 124, 7163; (b) T. C. Cook, M. B. Andrus and D. H. Ess, Org. Lett., 2012, 14, 5836.

8 (a) S.-s. Jew, B.-S. Jeong, M.-S. Yoo, H. Huh and H.-g. Park, Chem. Commun., 2001, 1244; (b) H.-g. Park, B.-S. Jeong, M.-S. Yoo, J.-H. Lee, M.-k. Park, J.-J. Lee, M.-J. Kim and S.-s. Jew, Angew. Chem., Int. Ed., 2002, 41, 3036; (c) J.-H. Lee, M.-S. Yoo, J.-H. Jung, S.-s. Jew, H.-g. Park and B.-S. Jeong, Tetrahedron, 2007, 63, 7906; (d) N. Baba, J. Oda and M. Kawaguchi, Agric. Biol. Chem., 1986, 50, 3113.

9 R. Chinchilla, P. Mazón and C. Nájera, Tetrahedron: Asymmetry, 2002, 13, 927.

10 J.-H. Lee, M.-S. Yoo, J.-H. Jung, S.-S. Jew, H.-G. Park and B.-S. Jeong, Tetrahedron, 2007, 63, 7906.

11 S. Bozkurt, M. Durmaz, M. Yilmaz and A. Sirit, Tetrahedron: Asymmetry, 2008, 19, 618.

12 (a) S. Itsuno, D. K. Paul, M. A. Salam and N. Haraguchi, J. Am. Chem. Soc., 2010, 132, 2864-2865; (b) M. M. Parvez, N. Haraguchi and S. Itsuno, Macromolecules, 2014, 47, 1922.

13 M. F. Geer, M. D. Walla, K. M. Solntsev, C. A. Strassert and L. S. Shimizu, J. Org. Chem., 2013, 78, 5568.

14 (a) K. Nahm and S. Lee, Bull. Korean Chem. Soc., 2012, 33, 2711; (b) E. F. Martins and J. R. Pliego Jr, ACS Catal., 2013, 3, 613.

15 (a) E. B. Fleischer, N. Sung and S. Hawkinson, J. Phys. Chem., 1968, 72, 4311; (b) R. Hoffmann and J. R. Swenson, J. Phys. Chem., 1970, 74, 415.

16 B. Lygo, J. Crosby, T. R. Lowdon, J. A. Peterson and P. G. Wainwright, Tetrahedron, 2001, 57, 2403.

17 (a) M. J. O'Donnell and S. Wu, Tetrahedron: Asymmetry, 1992, 3, 591; (b) B. Lygo, J. Crosby and J. A. Perterson, Tetrahedron Lett., 1999, 40, 8671; (c) S. s. Jew, B.-S. Jeong, J.-H. Lee, M.-S. Yoo, Y.-J. Lee, B.-s. Park, M. G. Kim and H.-g. Park, J. Org. Chem., 2003, 68, 4514. 